\title{
On the Market Portfolio for Multi-Asset Classes*
}

\author{
Rodolphe Louis \\ Research \& Development \\ Lyxor Asset Management, Paris \\ rodolphe.louis@lyxor.com
}

\author{
Thierry Roncalli \\ Research \& Development \\ Lyxor Asset Management, Paris \\ thierry.roncalli@lyxor.com
}

April 2012

\begin{abstract}
The influence of the CAPM theory on the financial theory of investment has increased with the development of passive management. Today, equity or fixed-income market portfolios can easily be defined using equity and fixed-income indexes. These indexes also play an important role in active management as they serve as benchmarks. The case of multi-asset classes is more complex. Indeed, indexes taking into account both stocks and bonds do not exist today. However, most investors need such references as their principal problem is to define their stock/bond asset mix policy. It is especially true for institutional investors like pension funds and long-term investors. In this article, we show how to compute the market portfolio of equity and fixed-income instruments. We then analyse the specificity of such a portfolio according to countries or regions and how this portfolio has changed over the last thirty years. The dynamics of the market portfolio also gives useful information about the evolution of ex-ante risk premia of stocks and bonds. Finally, we illustrate how the market portfolio could be used to benchmark diversified funds and to characterize the bets of long-term investment policy.
\end{abstract}

Keywords: market portfolio, stock, bond, benchmark, multi-assets allocation, active management, risk premium, strategic asset allocation, long-term investment policy.

\section{JEL classification: G1.}

\section{Introduction}

The concept of market portfolio has a long history and dates back to the seminal work of Markowitz (1952). In this paper, Markowitz defines precisely what portfolio selection means: "the investor does (or should) consider expected return a desirable thing and variance of return an undesirable thing". Indeed, Markowitz shows that an efficient portfolio is the portfolio that maximises the expected return for a given level of risk (corresponding to the variance of return). Markowitz concludes that there isn't only one optimal portfolio, but a set of optimal portfolios which is called the efficient frontier.

By studying the liquidity preference, Tobin (1958) shows that the efficient frontier becomes a straight line in the presence of a risk-free asset. In this case, optimal portfolios correspond to a combination of the risk-free asset and one particular efficient portfolio named

*We thank Raphael Dieterlen and Guillaume Lasserre for their helpful comments. 
the tangency portfolio. Sharpe (1964) summarizes the results of Markowitz and Tobin as follows: "the process of investment choice can be broken down into two phases: first, the choice of a unique optimum combination of risky assets ${ }^{1}$; and second, a separate choice concerning the allocation of funds between such a combination and a single riskless asset". This two-step procedure is today known as the Separation Theorem (Lintner, 1965).

One of the difficulties to compute the tangency portfolio is to precisely define the vector of expected returns of the risky assets and the corresponding covariance matrix of returns. In 1964, Sharpe develops the CAPM theory and highlights the relationship between the risk premium of the asset (the difference between the expected return and the risk-free rate) and its beta (the systematic risk with respect to the tangency portfolio). By assuming that the market is at equilibrium, he shows that the prices of assets are such that the tangency portfolio is the market portfolio, which is composed by all risky assets in proportion to their market capitalization. The major contribution of Sharpe has led to an increasing development of empirical investigations. Early empirical studies like Black et al. (1972) or Fama and MacBeth (1973) generally accept the validity of the CAPM theory. But, with the sophistication of econometric tests (Lewellen and Nagel, 2006) and the emergence of concurrent models (APT, Fama-French, etc.), the CAPM theory is today less accepted by academics $^{2}$ and professionals.

However, two concepts introduced by the seminal work of Sharpe continue to be extensively used in the asset management industry: the beta and the market portfolio. This last one has generated the fabulous development of indexes and passive management. Investing in US or Euro equities is today facilitated by the existence of indexes like the S\&P500 index or the Eurostoxx index among others, whereas the same conclusion holds for fixed-income instruments. The market portfolio has had also a major impact on the theory and practice of investment management as explained by Dimson and Mussavian (1999): "it is now common to view a managed portfolio as a blend of a passive portfolio (such as index fund) and an active portfolio comprising a series of bets on the relative performance of individual securities". This is particularly true for portfolios investing in one asset class like equities or bonds, but certainly not for portfolios investing in multi-asset classes. But as Roll (1977) points out, the market portfolio defined in the theoretical CAPM, is an index of multi-asset classes including of course (domestic) equities, but also bonds, foreign assets, etc.

It is also curious that investors refer to the market portfolio when they consider one specific asset class, but do not use it when they analyze their entire portfolio. This remark is particularly obvious for diversified funds which are generally benchmarked to a constant mix portfolio of an equity index and a fixed-income index. They express also their bets with respect to this constant mix benchmark. This remark is also valid for long-term investors like pension funds. They also quantify their bets by comparing their tactical asset allocation to their strategic asset allocation policy, but they never analyze them with respect to the market portfolio. One may explain this paradox, because indexes of multi-asset classes do not exist yet, certainly because index providers for equities are not the same than those for fixed-income instruments. But comprehensive data are available, especially since 10 years, and we could now build the market portfolio for multi-asset classes.

In this article, we restrict our analysis to stock/bond asset classes, because it is certainly the main challenge that face long-term investors: how much capital must be invested respectively in equities and bonds? In section 2, we show how to compute stock/bond market

\footnotetext{
${ }^{1}$ It is precisely the tangency portfolio.

${ }^{2}$ See e.g. Merton (1973), Roll (1977), Breeden (1979) or Fama and French (1996).
} 
On the Market Portfolio for Multi-Asset Classes

portfolios and compare them with respect to countries and regions. Then, we estimate the bond and equity risk premia priced by the market in Section 3. Section 4 is dedicated to the use of the market portfolio for benchmarking diversified funds and for characterizing the bets of long-term investment policies. Section 5 finally concludes.

\section{Computing the market portfolio for multi-asset classes}

Except the works of Roger Ibbotson (see for example Ibbotson and Fall, 1979 and Ibbotson and Siegel, 1983), the literature on the computation of the global market portfolio is very limited. It is certainly due to the fact that there isn't one data provider that gives the comprehensive data to compute it. However, it is easier to compute this global market portfolio since ten years because of the development of financial databases. One of the difficulties is to choose the right sources ${ }^{3}$ and to combine them.

As mentioned above, we restrict our analysis to the stock/bond market portfolio, because this asset mix policy is the main contributor of the performance of long-term investors (Brinson et al., 1991). In this section, we first precise how to characterize the market portfolio and illustrate its behavior for several countries. Then, we consider the construction of the multi-currency market portfolio.

\subsection{The single-currency market portfolio}

\subsubsection{Characterization of the market portfolio}

Let us first consider the single-country case. We assume that we could associate to this country the universe $\mathcal{A}$ of the corresponding financial domestic assets. At time $t$, the share number and the price of asset $i$ are denoted respectively $N_{i}(t)$ and $P_{i}(t)$. The market capitalization for this country is defined as follows:

$$
\operatorname{MC}(t ; \mathcal{A})=\sum_{i \in \mathcal{A}} N_{i}(t) P_{i}(t)
$$

We assume that we could divide the set $\mathcal{A}$ into $m$ disjoint subsets $\mathcal{A}_{j}$ :

$$
\mathcal{A}=\biguplus \mathcal{A}_{j}
$$

In this case, we could compute the market capitalization for the subset $\mathcal{A}_{j}$ :

$$
\operatorname{MC}\left(t ; \mathcal{A}_{j}\right)=\sum_{i \in \mathcal{A}_{j}} N_{i}(t) P_{i}(t)
$$

We could also characterize the market portfolio by the weights $\left(w_{1}, \ldots, w_{j}, \ldots, w_{m}\right)$ associated to the different subsets with:

$$
w_{j}=\frac{\mathrm{MC}\left(t ; \mathcal{A}_{j}\right)}{\mathrm{MC}(t ; \mathcal{A})}
$$

Because the subsets are disjoint, we verify that the sum of the weights is equal to 1 :

$$
\sum_{j=1}^{m} w_{j}=1
$$

\footnotetext{
${ }^{3}$ The cost of these databases is also another problem for academics and explain certainly the lack of empirical works on this topic.
} 
In general, the subsets correspond to asset classes. These asset classes may be large like equity, bond, commodity, etc. Or they may be more specific like equity large caps, equity small caps, sovereign bonds, corporate investment grade bonds, high yield bonds, etc. In this section, we only consider the stock/bond market portfolio. We define the equity market capitalization $\mathrm{MC}(t ; \mathcal{E})$ of the country by considering all the equity stocks which are traded in the financial market of this country. In the same way, we could define market capitalization of bonds $\mathrm{MC}(t ; \mathcal{B})$. Therefore, we could characterize the market portfolio by the relative proportion of equities $w(t ; \mathcal{E})$ in the total market capitalization. We have:

$$
w(t ; \mathcal{E})=\frac{\mathrm{MC}(t ; \mathcal{E})}{\mathrm{MC}(t ; \mathcal{E})+\mathrm{MC}(t ; \mathcal{B})}
$$

\subsubsection{With equities and sovereign bonds}

One of the difficulties is to obtain all the data to compute $\operatorname{MC}(t ; \mathcal{E})$ and $\operatorname{MC}(t ; \mathcal{B})$. For example, for the United States, there are more than several thousands stocks traded in the different financial markets located in this country. That's why it is easier to consider a broad index to approximate the market capitalization. In the case of the United States, we could use the Wilshire 5000 Index. For Japan, the Topix index is a good candidate. One of the problems with these indexes is that they are regional. So, they don't follow the same rules of construction. That's why we prefer to use the Datastream equity indexes in order to keep homogeneity between data ${ }^{4}$ and the Datastream sovereign bond indexes.

In Figures 1 and 2, we report the evolution of $w(t ; \mathcal{E})$ since 1980 for United States and Japan. We notice two main facts:

- First, the weight $w(t ; \mathcal{E})$ varies over time. For example, it reaches $89 \%$ in September 2000 whereas it is equal to $55 \%$ in December 1987 for the United States. This timevarying property is mainly due to the volatility of equity prices. We also notice that the 2008 financial crisis has a bigger impact on this ratio than the dot.com bubble crisis after 2000.

- Second, we observe large differences between countries. For example, during the nineties, the weight $w(t ; \mathcal{E})$ increases in the US whereas it decreases for Japan. We also notice that the behavior of Germany and France is very different from US and UK. This is particularly true during the dot.com bubble. In March 2012, the ratio takes the value of $67.5 \%$ for US, $32.2 \%$ for Japan, $51.0 \%$ for Germany, $53.7 \%$ for France and $66.0 \%$ for UK.

These first results show that it is difficult to characterize the market portfolio by fixed weights. The stock/bond market portfolio could not be viewed as a constant mix portfolio. However, a lot of institutional investors define their asset allocation policy as constant mix policy. It implies that most institutional investors have a behavior different than the global market. As noticed by Sharpe (2010), they are contrarian whereas the market is globally trend-following.

In Table 1 , we have reported the statistic $w(t ; \mathcal{E})$ for several countries and the last eight years. We verify the trend-following property of the market portfolio particularly for the period of the 2008 financial crisis. But we also notice how different is the impact of this crisis between countries. Its impact is high in Netherlands or Italy whereas it is limited in Australia or Sweden.

\footnotetext{
${ }^{4} \mathrm{MSCI}$ equity indexes are another good solution.
} 
Figure 1: Evolution of the equity weight for United States and Japan

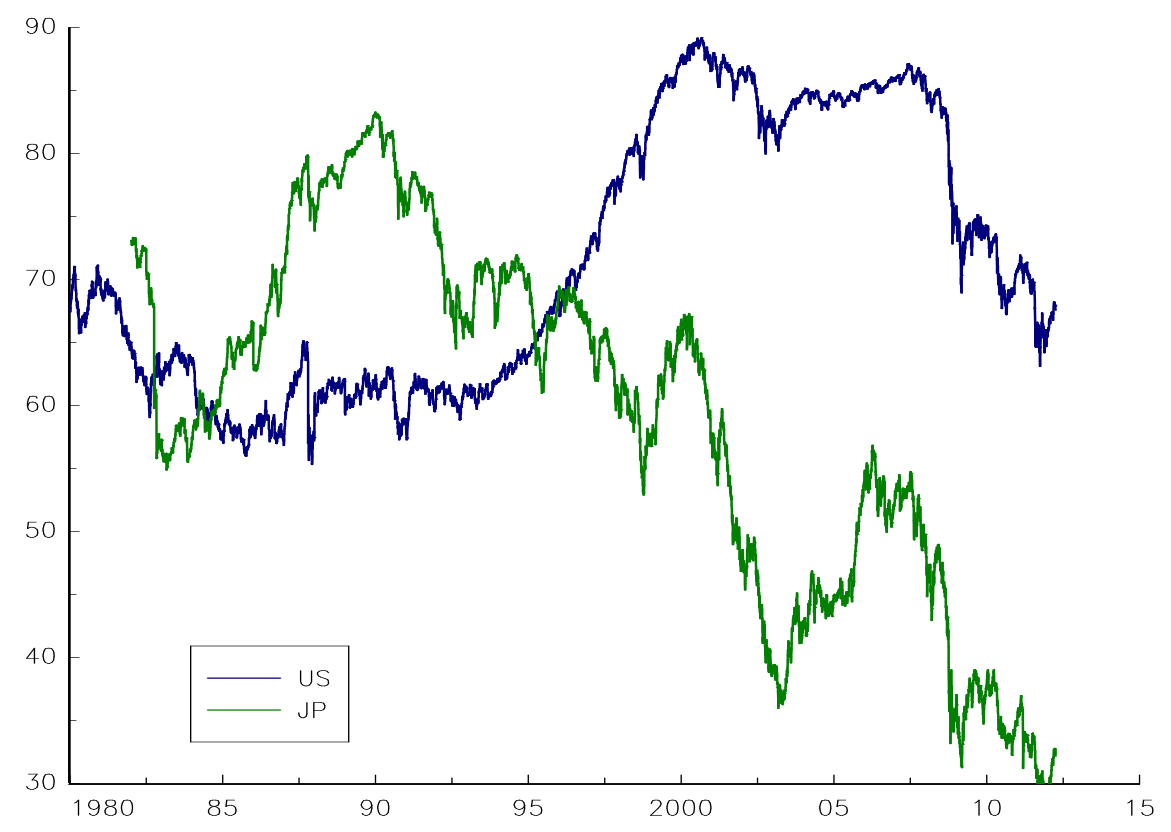

Figure 2: Evolution of the equity weight for Germany, France and United Kingdom

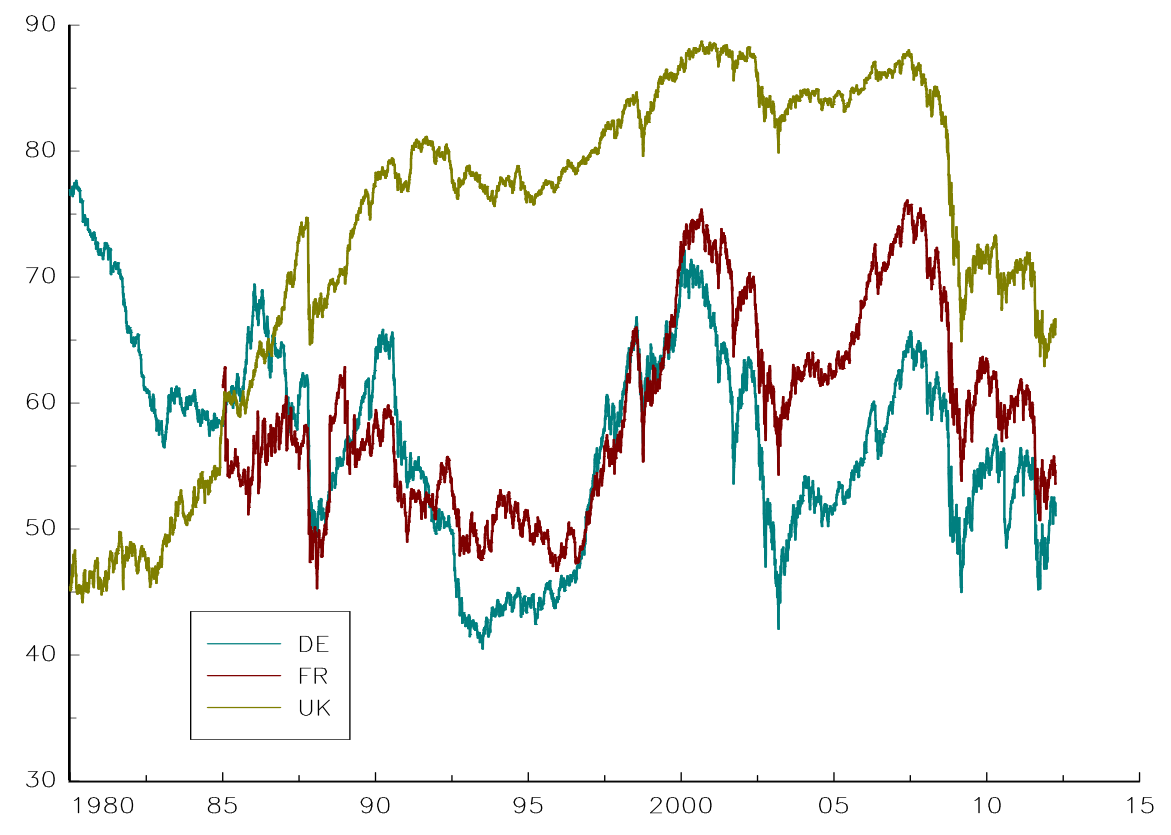


On the Market Portfolio for Multi-Asset Classes

Table 1: Weight $w(t ; \mathcal{E})$ of equities (in \%) at the beginning of each year

\begin{tabular}{c|cccccccc}
\hline Year & 2005 & 2006 & 2007 & 2008 & 2009 & 2010 & 2011 & 2012 \\
\hline US & 84.9 & 85.2 & 85.9 & 85.8 & 75.0 & 73.8 & 70.6 & 65.7 \\
JP & 44.9 & 53.8 & 52.9 & 49.8 & 36.3 & 37.6 & 34.6 & 29.4 \\
DE & 52.0 & 55.5 & 60.9 & 64.2 & 50.6 & 56.0 & 54.0 & 47.5 \\
FR & 62.5 & 67.7 & 72.8 & 74.1 & 59.7 & 62.7 & 59.9 & 53.0 \\
UK & 83.9 & 84.9 & 86.7 & 85.5 & 72.8 & 72.0 & 70.8 & 64.3 \\
IT & 45.3 & 48.4 & 53.6 & 51.7 & 35.3 & 34.6 & 32.0 & 28.5 \\
AU & 95.0 & 96.0 & 96.5 & 97.0 & 94.4 & 93.2 & 90.1 & 84.4 \\
NL & 70.7 & 70.4 & 75.5 & 75.4 & 55.6 & 61.1 & 59.8 & 51.2 \\
SE & 78.6 & 83.2 & 86.7 & 86.6 & 80.2 & 83.7 & 86.5 & 83.8 \\
\hline
\end{tabular}

Computing the weights of the market portfolio is important, but analysing the performance of such portfolio is crucial to understand how the wealth due to equities and bonds evolve. Let $I(t ; \mathcal{B})$ and $I(t ; \mathcal{E})$ be the value of the bond and equity indexes. The market portfolio is rebalanced at each date according to the market capitalization. Its return at time $t$ is then:

$$
R(t)=w(t-1 ; \mathcal{B}) \cdot R(t ; \mathcal{B})+w(t-1 ; \mathcal{E}) \cdot R(t ; \mathcal{E})
$$

where $R(t ; \mathcal{B})=I(t ; \mathcal{B}) / I(t-1 ; \mathcal{B})-1$ and $R(t ; \mathcal{E})=I(t ; \mathcal{E}) / I(t-1 ; \mathcal{E})-1$ are the returns of bonds and equities. In Figure 3, we have reported the performance of the market portfolio for several countries ${ }^{5}$. We notice the poor performance of the Japanese market portfolio compared to the other developed countries market portfolio. Another interesting

Figure 3: Performance of the market portfolio

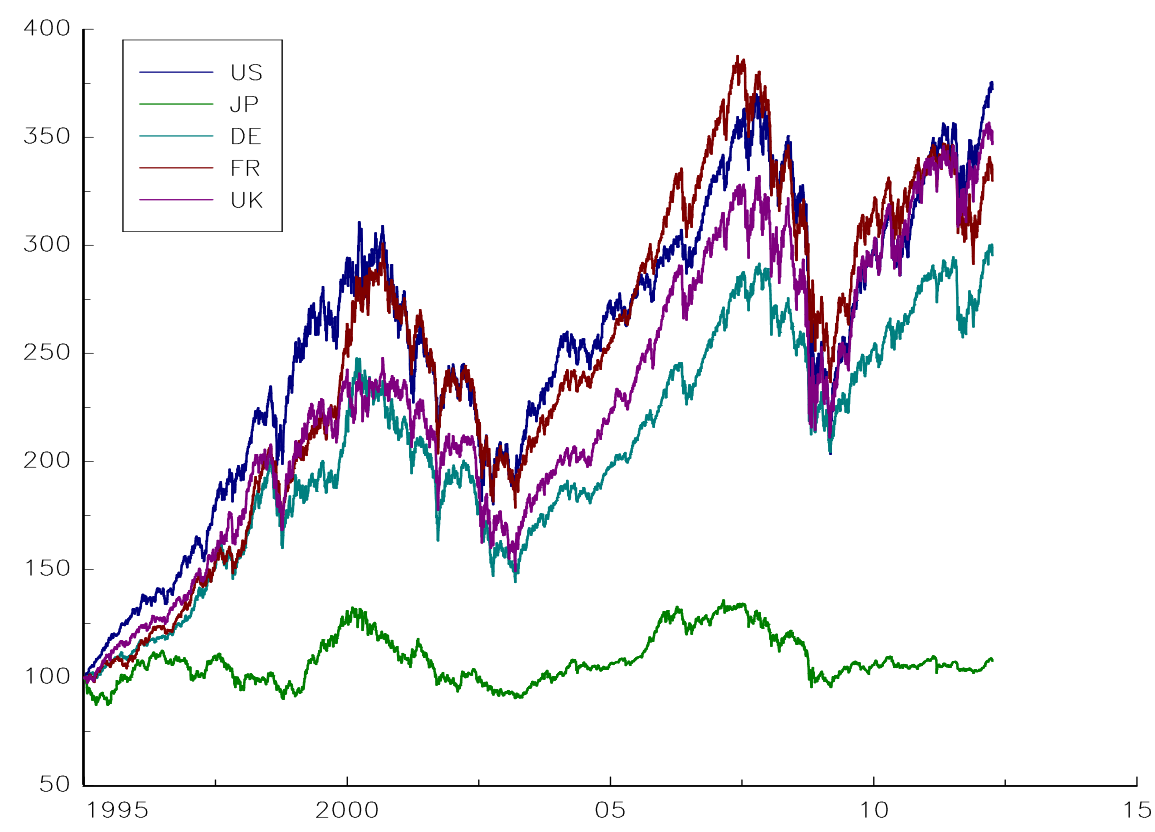

\footnotetext{
${ }^{5}$ The portfolio is rebalanced in a daily basis.
} 
On the Market Portfolio for Multi-Asset Classes

fact is the difference in terms of return, but even more in terms of risk, between Germany and France, the two countries which are the pillars of the Eurozone. Indeed, the French market portfolio systematically outperforms the German market portfolio during economic expansions whereas it is the contrary during the economic crisis (the 2000 dot.com bubble and the 2008 financial crisis).

\subsubsection{With equities and investment grade bonds}

In the previous paragraph, we have only considered government bonds. We could extend the bond universe by considering all the bonds which are investment grade ${ }^{6}$. In this case, we have to consider other non-government sovereign bonds (like sovereign guaranteed, sponsored and regional government categories), collateralized bonds (MBS and ABS) and corporate bonds. For the application, the Datastream equity indexes are used whereas we prefer to consider the World BIG, US BIG and Euro Big sub-indexes provided by Citygroup which are recognized to be one of the best data sources by professionals. The evolution of the equity weight is represented in Figure 4 for US and Eurozone. We verify that the equity weight is larger in the US than in the Eurozone because of the large development of the equity market in the US. We confirm that the stock/bond allocation of the market portfolio varies over time. For US, equity varies between a 40\% - 75\% range between 1985 and 2012 . For the Eurozone, the range is between $30 \%$ and $65 \%$.

Figure 4: Evolution of the Equity weight for US and Eurozone

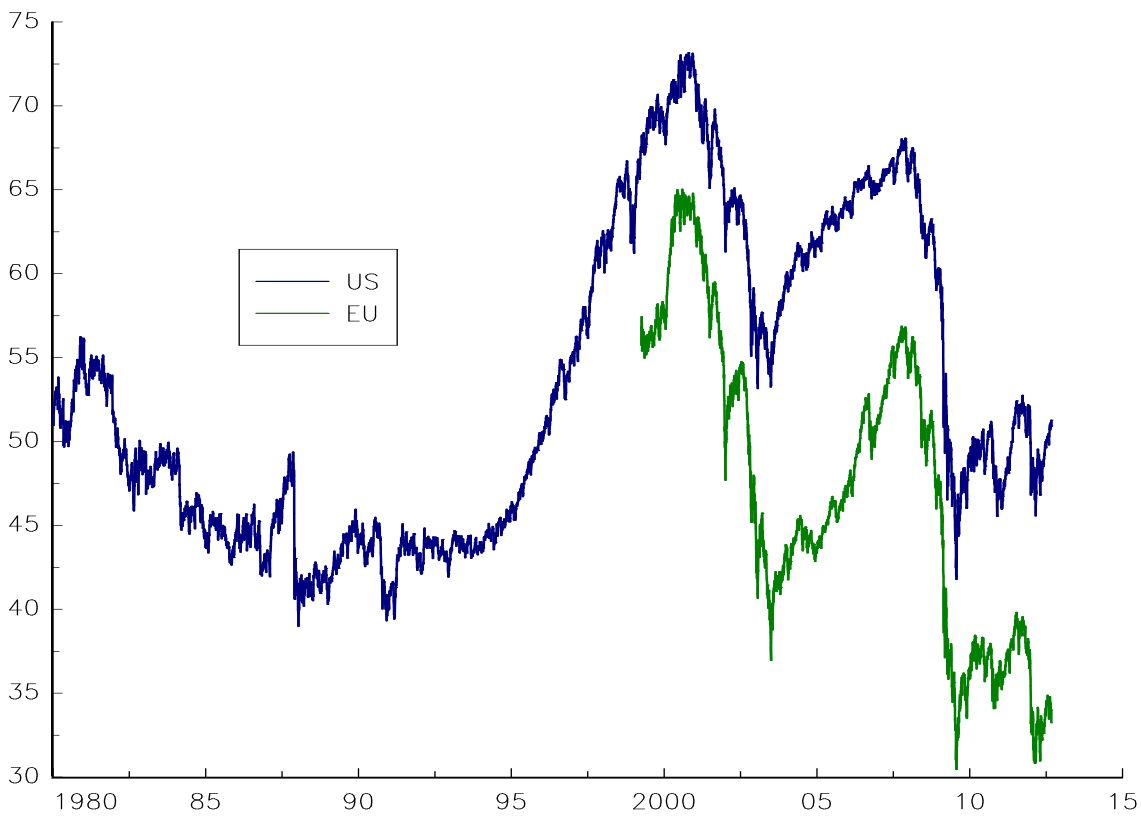

In Table 2, we have reported the allocation between equities and bonds year by year. Moreover, we have indicated the split between sovereign, collateralized and corporate bonds. In the bond allocation, we observe some big differences between the US and the Eurozone. Indeed, collateralized and corporate bonds represent a smaller part in the Eurozone. At the

\footnotetext{
${ }^{6} \mathrm{~A}$ bond is considered investment grade if its credit rating is BBB- or higher by Standard \& Poor's.
} 
On the Market Portfolio for Multi-Asset Classes

beginning of 2012, the stock/bond allocation is close respectively to a 50/50 allocation in the US and 30/70 in the Eurozone. Seven years ago, it was respectively $65 / 35$ and $45 / 55$. Since the beginning of 1999, the yearly volatility of the exposure relative variations is equal to $9.7 \%$ for equities, $13.5 \%$ for sovereign bonds, $12.9 \%$ for collateralized bonds and $13.5 \%$ for corporate bonds in the US. In the Eurozone, the yearly volatility of the exposures becomes $11.5 \%, 9.6 \%, 11.8 \%$ and $12.2 \%$. We observe also a curious fact between US and Eurozone. Equity weights are more volatile than sovereign bond weights in the Eurozone, whereas it is the contrary in the US. If we now consider the turnover, it is equal to $113.4 \%$ in the US and $113.3 \%$ in the Eurozone. So, the typical turnover of a multi-asset classes market portfolio is close to $100 \%$ by year, meaning that we completely rebalance the portfolio one time in the year. Another interesting result concerns the monthly cross-correlation of the weight absolute variations between US and Eurozone. For equities, it is equal to $85 \%$ whereas it is lower but remains high for bonds ( $78 \%$ for sovereign bonds, $75 \%$ for collateralized bonds and $65 \%$ corporate bonds) ${ }^{7}$.

Table 2: Market portfolio allocation (in \%) at the beginning of each year

\begin{tabular}{|c|c|c|c|c|c|c|c|c|c|}
\hline & Year & 2005 & 2006 & 2007 & 2008 & 2009 & 2010 & 2011 & 2012 \\
\hline \multirow{5}{*}{ US } & Equity & 63.7 & 65.0 & 66.2 & 65.2 & 49.9 & 49.6 & 50.0 & 48.7 \\
\hline & Bond & 36.3 & 35.0 & 33.8 & 34.8 & 50.1 & 50.4 & 50.0 & 51.3 \\
\hline & ${ }^{-}$Sovereign & 14.0 & $1 \overline{3} . \overline{8}$ & $1 \overline{2} . \overline{9}$ & $1 \overline{2} . \overline{5}$ & $1 \overline{8} . \overline{3}$ & $1 \overline{8} . \overline{8}$ & $\overline{2} \overline{1} . \overline{5}$ & $\overline{2} \overline{2} . \overline{2}$ \\
\hline & Collateralized & 13.1 & 12.6 & 12.6 & 13.7 & 20.7 & 19.0 & 16.3 & 16.6 \\
\hline & Corporate & 9.2 & 8.6 & 8.3 & 8.6 & 11.1 & 12.7 & 12.2 & 12.6 \\
\hline \multirow{5}{*}{ Euro } & Equity & 45.2 & 49.5 & 53.8 & 53.9 & 37.3 & 37.7 & 37.7 & 33.2 \\
\hline & Bond & 54.8 & 50.5 & 46.2 & 46.1 & 62.7 & 62.3 & 62.3 & 66.8 \\
\hline & $-\overline{\text { Sover }}$ & $\overline{41} . \overline{2}$ & $-\overline{8} . \overline{6}$ & $3 \overline{4} . \overline{8}$ & $3 \overline{3} . \overline{2}$ & $4 \overline{5} . \overline{1}$ & $-4 \overline{4} . \overline{3}$ & $\overline{-} 4 \overline{4} . \overline{0}$ & $\overline{4} \overline{7} . \overline{2}$ \\
\hline & Collat & 7.0 & 6.4 & 6.6 & 7.0 & 9.0 & 7.1 & 7.3 & 8.5 \\
\hline & Corporate & 6.6 & 5.6 & 4.9 & 5.9 & 8.6 & 10.9 & 11.0 & 11.2 \\
\hline
\end{tabular}

\subsection{The multi-currency market portfolio}

The theory of market portfolio with currency risk is a little bit more complicated than the original CAPM theory ${ }^{8}$. It implies that the market portfolio is also composed of some currency exposures ${ }^{9}$. But empirical investigations show that they may be considered as residual exposures. That's why we directly generalize the previous framework by considering the US dollar as the reference currency to compute the weights ${ }^{10}$. But, for the performance of the market portfolio, we consider two methods, one which ignores currency risks and another one which perfectly hedges them ${ }^{11}$.

Let us consider the 'developed countries' market portfolio. In this application, the term 'developed countries' refers to Australia, Canada, Denmark, Eurozone, Japan, Norway, New

\footnotetext{
${ }^{7}$ If we consider the relative variations, these figures become $62 \%$ for equities, $55 \%$ for sovereign bonds, $47 \%$ for collateralized bonds and $49 \%$ for corporate bonds.

${ }^{8}$ See Adler and Dumas (1983).

${ }^{9}$ We notice that the principal reason of an overlay portfolio is to manage the currency risks. Overlay asset management has then theoretical foundations and may be justified by CAPM.

${ }^{10}$ One of the main differences with the previous framework is the increase of the volatility of weights due to the volatility of foreign exchange rates.

${ }^{11}$ We do not consider a third solution, which consists in using the optimal hedge ratio developed by Black (1989).
} 
On the Market Portfolio for Multi-Asset Classes

Zealand, Sweden, Switzerland, UK and US countries. We also build a 'world' market portfolio by including to the DC universe the following countries: Argentina, Brazil, Bulgaria, Chile, China, Czech Republic, Egypt, Hong Kong, Hungary, India, Indonesia, Israel, Korea, Mexico, Peru, Philippine, Poland, Romania, Russia, South Africa, Singapore, Slovenia, Taiwan, Thailand, Turkey and Venezuela. Results are reported in Figure 5. By including some emerging markets, the equity weight increases, because bonds of these countries are generally non investment grade. The performance of the DC and World market portfolios is reported in Figure 6. To compute the performance, we consider two cases by considering or not currency risks. In the first case, the performance is directly expressed in US dollars and takes into account foreign exchange risks. In the second case (hedged), currency risks against USD are hedged. We notice that performance is better when we do not hedge currency risks. The reason is that US dollar has been generally depreciated since $1999^{12}$. Since 1999, the annualized return is respectively $4.33 \%$ (DC changed), $4.97 \%$ (World changed), $3.62 \%$ (DC hedged) and $4.03 \%$ (World hedged). The volatility is between $8.99 \%$ (DC hedged) and $10.54 \%$ (World changed). In the same time, the performance of the Libor US is equal to $2.85 \%$. Therefore, we obtain poor Sharpe ratios (between $8.6 \%$ and $20 \%$ ). We also notice that the drawdown of these market portfolios is high. It is respectively equal to $34.1 \%$ (DC changed), 38.2\% (World changed), 30.3\% (DC hedged) and 34.1\% (World hedged).

Figure 5: Evolution of the Equity weight for DC and World market portfolios

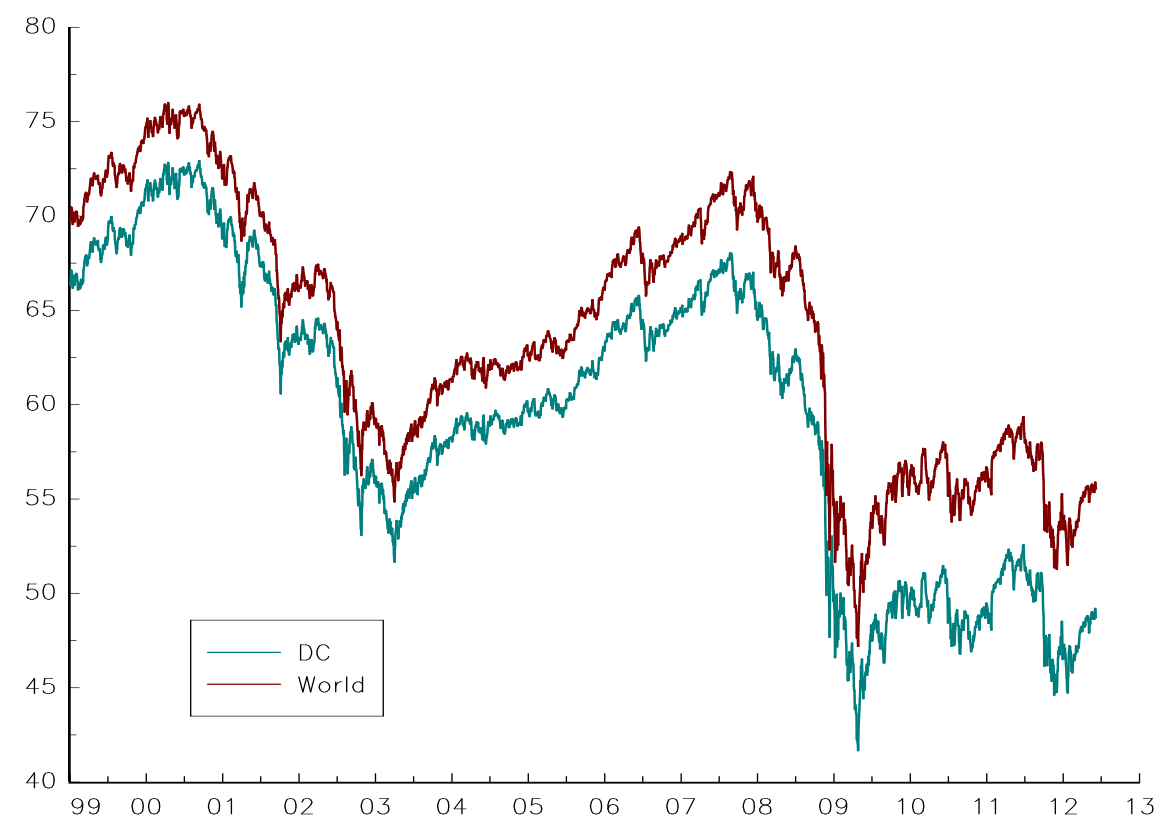

The dynamics of these market portfolios may be analyzed from the asset classes point of view, but also from the country or region point of view. In Table 3, we have reported the allocation at the beginning of the year between 2005 and 2012. We notice that the weight of the US remains stable, whereas the weight of the Eurozone decreases slightly, in particular since 2008. We observe the large weights of other countries than US and Euro in the DC

\footnotetext{
${ }^{12}$ When we compute the difference between the changed and hedged performances and compute the correlation of this difference with the US dollar index, we have a correlation close to 1.
} 
Figure 6: Performance of DC and World market portfolios

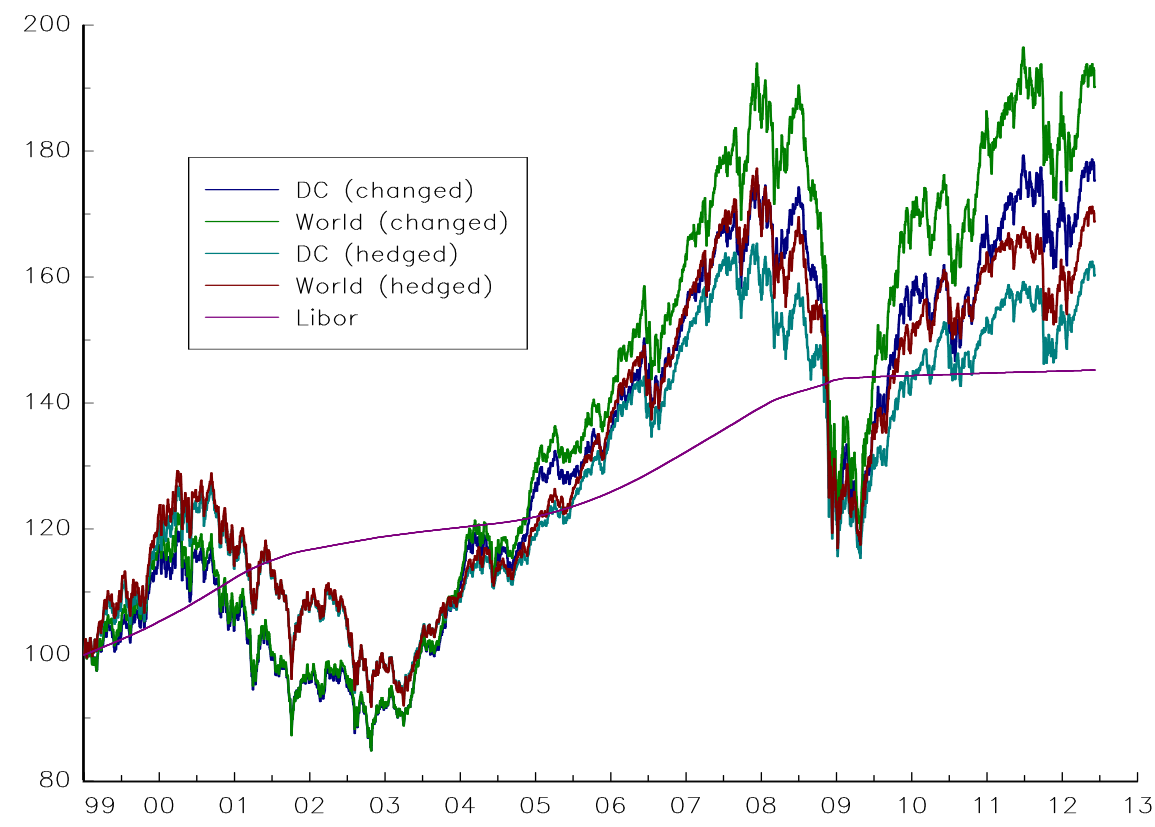

market portfolio. This result contrasts with for example the repartition of the MSCI world index. The differences come principally from the inclusion of bonds ${ }^{13}$. Another interesting fact is the importance of the emerging countries in the world market portfolio. Indeed, we observe that the weight of these countries has increased by $80 \%$ since 2005 .

Table 3: Market portfolio allocation (in \%) at the beginning of each year

\begin{tabular}{|c|c|c|c|c|c|c|c|c|}
\hline & Year & 2005 & 2007 & 2008 & 2009 & 2010 & 2011 & 2012 \\
\hline \multirow{5}{*}{$\mathrm{DC}$} & Equity & 60.3 & 65.4 & 64.6 & 48.1 & 50.2 & 50.8 & 46.8 \\
\hline & $\bar{B}^{-} \bar{n}^{-}$ & $\overline{-} \overline{9} . \overline{7}$ & $\overline{3} \overline{4} . \overline{6}$ & $\overline{3} \overline{5} . \overline{4}$ & $\overline{5} \overline{1} . \overline{9}$ & $\overline{4} \overline{9} . \overline{8}$ & $\overline{4} \overline{9} . \overline{2}$ & $\overline{5} \overline{3} . \overline{2}$ \\
\hline & US & 45.2 & 42.6 & 41.7 & 43.2 & 43.4 & 45.3 & 46.1 \\
\hline & $\overline{\text { E}} \overline{\text { uro }}$ & $2 \overline{5} . \overline{4}$ & $\overline{2} \overline{6} . \overline{2}$ & $\overline{2} \overline{7} . \overline{9}$ & $\overline{2} \overline{7} . \overline{3}$ & $\overline{2} \overline{7} . \overline{1}$ & $\overline{2} \overline{3} . \overline{3}$ & $\overline{2} \overline{2} . \overline{5}$ \\
\hline & Ōthers & $2 \overline{9} . \overline{4}$ & $3 \overline{1} . \overline{2}$ & $\overline{3} \overline{0} . \overline{4}$ & $\overline{2} \overline{9} . \overline{5}$ & $\overline{2} \overline{9} . \overline{5}$ & $\overline{3} \overline{1} . \overline{4}$ & $\overline{3} \overline{1} . \overline{5}$ \\
\hline \multirow{4}{*}{ World } & Equity & 63.2 & 69.3 & 69.9 & 53.1 & 56.7 & 57.8 & 53.3 \\
\hline & $\bar{B}^{-} \overline{n o n d}^{-}$ & $\overline{3} \overline{6} . \overline{8}$ & $\overline{3} \overline{0} \overline{7}$ & $\overline{3} \overline{0} . \overline{1}$ & $\overline{4} \overline{6} . \overline{9}$ & $\overline{4} \overline{3} . \overline{3}$ & $\overline{4} \overline{2} . \overline{2}$ & $\overline{4} \overline{6} . \overline{7}$ \\
\hline & $\mathrm{DC}$ & 93.6 & 89.2 & 85.8 & 90.9 & 87.6 & 86.1 & 88.3 \\
\hline & $\overline{\mathrm{E}} \overline{\mathrm{M}}^{-}$ & $\overline{6} . \overline{4}$ & $\overline{1} \overline{0} . \overline{8}$ & $\overline{1} \overline{4} . \overline{2}$ & $\overline{9} . \overline{1}$ & $\overline{1} \overline{2} \overline{4}$ & $13 \overline{0}$ & $\overline{1} \overline{1} \overline{7}$ \\
\hline
\end{tabular}

\section{$3 \quad$ Estimating bond and equity risk premia}

In this section, we use the materials developed by Black and Litterman $(1991,1992)$ to estimate the risk premium of bonds and equities. These implied (or ex-ante) risk premia

\footnotetext{
${ }^{13}$ The small caps effect is negligible.
} 
differ from the observed (or ex-post) risk premia, because they may be viewed as the price of the risk at the market equilibrium.

\subsection{From market portfolios to risk premia}

We may show that Markowitz portfolios are solution of a utility maximization program. More precisely, the utility function is a quadratic function which depends on the vector $\pi$ of expected excess returns ${ }^{14}$ and the covariance matrix $\Sigma$ of asset returns:

$$
U(w)=\pi^{\top} w-\frac{\lambda}{2} w^{\top} \Sigma w
$$

We could chose the parameter $\lambda$ in order to match a given volatility for the portfolio $w$. The solution of this utility maximization program is:

$$
w^{\star}=\frac{1}{\lambda} \Sigma^{-1} \pi
$$

In the Markowitz problem, the unknown variable is the vector of weights $w$. If we suppose that the optimal solution is given, we could deduce the implied expected excess return:

$$
\pi^{\star}=\lambda \Sigma w^{\star}
$$

In the formula (1), the parameters are $w^{\star}, \Sigma$ and $\lambda$. In practice, $w^{\star}$ is known and $\Sigma$ could be estimated using the empirical covariance matrix $\hat{\Sigma}$. $\lambda$ is a risk-aversion parameter and we have to calibrate it. We notice that $\pi^{\star}$ is proportional to $\lambda$ meaning that the relative differences of expected return between assets do not depend on $\lambda$. $\lambda$ is then an arbitrary constant. But in order to produce realistic values of $\pi^{\star}$, we could deduce $\lambda$ from the assumption of a constant Sharpe ratio:

$$
\operatorname{sh}\left(w^{\star}\right)=\frac{\pi^{\star \top} w^{\star}}{\sqrt{w^{\star \top} \Sigma w^{\star}}}=\operatorname{sh}^{\star}
$$

We deduce that:

$$
\lambda=\frac{\operatorname{sh}^{\star}}{\sqrt{w^{\star \top} \Sigma w^{\star}}}
$$

We finally obtain:

$$
\pi^{\star}=\frac{\operatorname{sh}^{\star}}{\sqrt{w^{\star \top} \Sigma w^{\star}}} \Sigma w^{\star}
$$

\subsection{Empirical findings}

We have calibrated the ex-ante risk premia using a one-year empirical covariance matrix and the assumption that the Sharpe ratio is constant and equal to 25\%. In Figure 7, we have reported the values taken by the ex-ante risk premia for the US market portfolio. First, we notice that the equity risk premium is larger than the bond risk premium. In average, for the considered period, it is equal to $4.5 \%$ for equity, 9 bps for bonds and only 3 bps for US treasury bonds. Second, we observe a large variation of this risk premium, especially for equities. This is due to the volatility of this asset class. Third, we verify that the risk

\footnotetext{
${ }^{14}$ Let $\mu$ and $r$ be the vector of expected returns and the risk-free rate. $\pi=\mu-r$ is also the vector of risk premia.
} 
premium of sovereign bonds is always smaller than the risk premium of investment grade bonds.

To understand these results, we could rewrite the previous expression (2) in the following way:

$$
\pi^{\star}=\operatorname{sh}^{\star} \frac{\partial \sigma\left(w^{\star}\right)}{\partial w}
$$

where $\sigma(w)$ is the volatility of the portfolio $w$. In this case, the risk premium is proportional to the marginal volatility. If one asset has a smaller marginal volatility than another one, then it has a smaller risk premium. Let us consider the two-asset case. We have:

$$
\pi_{i}^{\star}=\underbrace{c \sigma_{i}^{2} w_{i}^{\star}}_{\text {variance }}+\underbrace{c \rho \sigma_{i} \sigma_{j}\left(1-w_{i}^{\star}\right)}_{\text {covariance }}
$$

with $c=\operatorname{sh}^{\star} / \sigma\left(w^{\star}\right)$. We notice that there are two components in the risk premium. The first one is a variance component and is an increasing function of the volatility and the weight of the asset. The higher its volatility, the higher its risk premium. The second component is a covariance component and depends on the correlation between the asset returns. If the correlation $\rho$ is zero, the covariance component vanishes. The contribution of this component is positive only if the correlation is positive. It means that a low volatility asset could benefit from a high volatility asset in terms of risk premium if the correlation is high.

Figure 7: Ex-ante risk premia for the US market portfolio

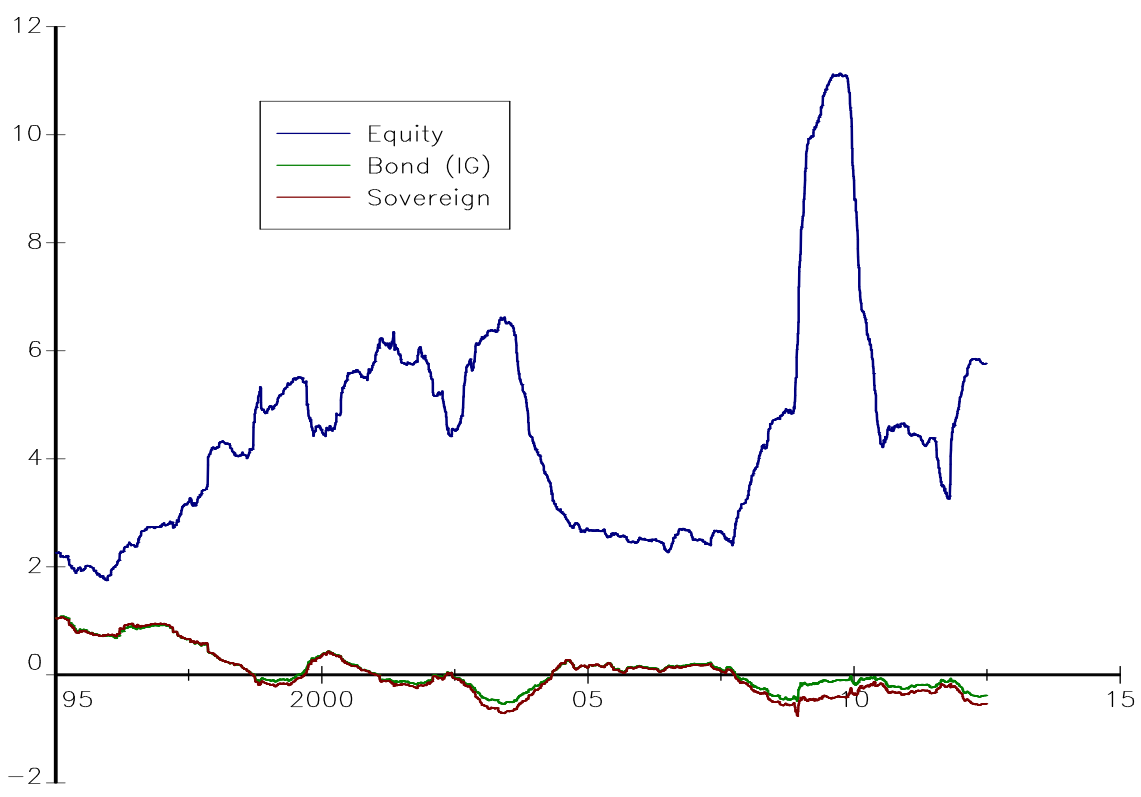

For the US, the volatility of equities and bonds is respectively equal to $18 \%$ and $4 \%$ in average for the considered period. The cross-correlation is close to zero, but it varies a lot across periods. For example, since the 2008 financial crisis, it is negative and around $-35 \%$. 
Figure 8: Difference between ex-ante EURO and US risk premia

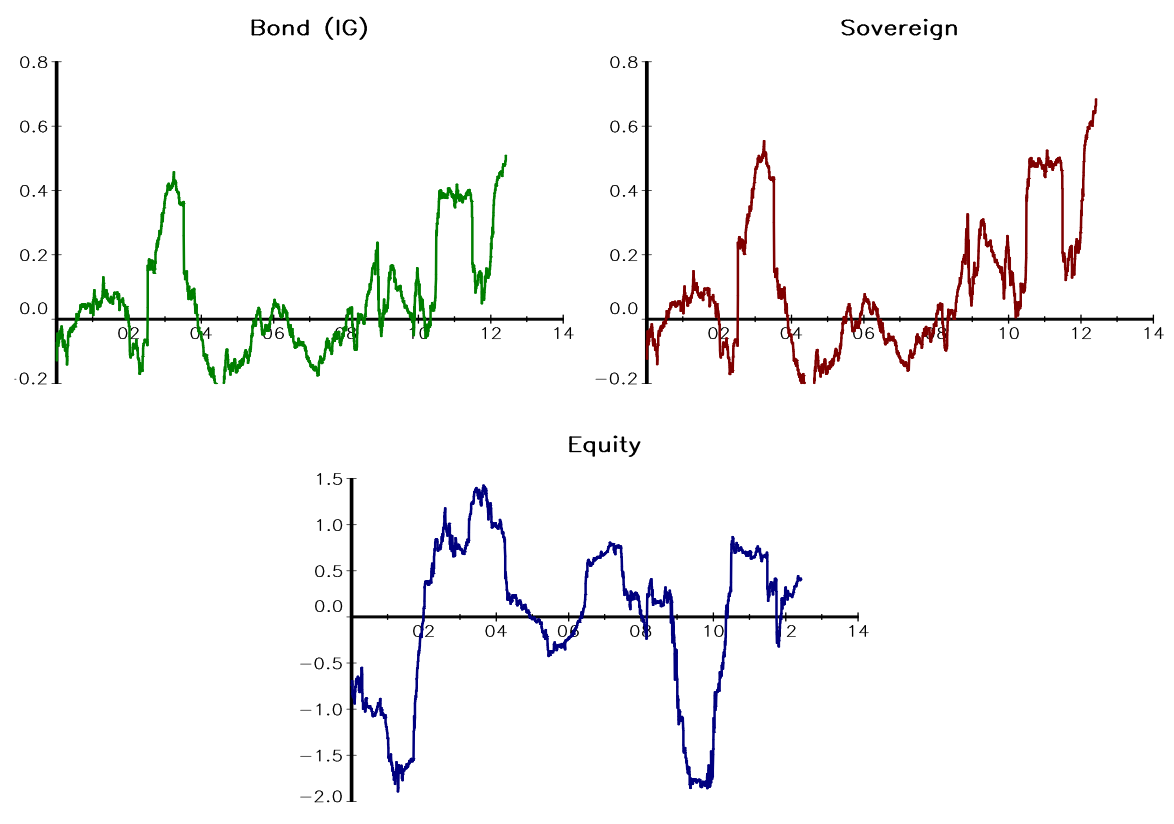

In this case, bonds could not exhibit a high risk premium ${ }^{15}$. In a similar way, the volatility peak in 2008 explains the high risk premium asked by investors for equities.

\section{Some implications for benchmarking and strategic as- set allocation}

The computation of the market portfolio could help investors and asset managers in their portfolio choice. It is particularly true for diversified and multi-asset funds. Generally, the identification of their benchmark is not obvious. However, the market portfolio is a natural candidate for benchmarking these funds. It could also be used as an analytical tool for strategic asset allocation, because it provides some interesting information for long-term investors.

\subsection{Benchmarking diversified, total return and risk parity funds}

Benchmarking an equity or a fixed-income fund is relatively easy. For example, in the case of an equity fund invested in US stocks, a natural benchmark will be the Dow Jones (Industrial Average) index or the S\&P 500 index. If the investment style presents some bias, we could use more specific benchmarks like MSCI US Growth or Value indexes. For fixed-income investment, large or specific indexes are also available. Beside the portfolio management of these two asset classes, there are other investment styles which are more difficult to benchmark. Hedge funds, private equity or commodity are some examples. Another example would be the large part of the asset management industry which invests

\footnotetext{
${ }^{15}$ With these figures, the upper bound of the bond risk premium is equal to $100 \mathrm{bps}$ and is reached for a market portfolio fully invested in bonds.
} 
both in equities and bonds. It concerns the industry of diversified funds, total return funds, absolute return funds, etc. The idea of this investment style is to invest both in equities and bonds and to change the proportion of these asset classes dynamically according to the views of the portfolio manager. Some diversified funds impose some restrictions on the allocation (for example, the proportion of bonds is always larger than 50\%) whereas the allocation is not constrained for total return funds. For these funds, the traditional benchmark is a composite portfolio of an equity index and a fixed-income benchmark with fixed weights. One of the most used benchmark is 50\% MSCI World index + 50\% Citygroup WBIG index.

Let us for example consider a risk parity fund. It is a multi-asset strategy (generally on equities and bonds) where the portfolio is managed according to the equally weighted risk contribution portfolios (Maillard et al., 2010). Let $\sigma(w)=\sqrt{w^{\top} \Sigma w}$ be the volatility of the portfolio $w$. We may show that the volatility satisfies the Euler decomposition meaning that it could be decomposed as follows:

$$
\sigma(w)=\sum_{i=1}^{n} \underbrace{w_{i} \times \frac{\partial \sigma(w)}{\partial w_{i}}}_{\mathrm{RC}_{i}}
$$

The weight times the marginal risk is called the risk contribution. An ERC portfolio is defined such that the risk contributions are the same for all the components of the portfolio:

$$
\mathrm{RC}_{i}=\mathrm{RC}_{j}
$$

This portfolio presents some appealing properties (Maillard et al., 2010). In particular, it is located between the minimum-variance portfolio and the equally weighted $(1 / \mathrm{n})$ portfolio. Moreover, it is the portfolio which minimizes the risk concentration according to the Gini criterion (Hereil and Roncalli, 2011). When we apply the ERC portfolio to the universe of the Eurostoxx 50 index, it is natural to take the Eurostoxx 50 index as the benchmark. But for risk parity funds on multi-asset classes, the choice of the benchmark is not easy. One of the most used by academics is the traditional 60/40 portfolio of stocks/bonds (Chaves et al., 2011, Asness et al., 2012). This benchmark is also used by several risk parity funds, like the Invesco Balanced-Risk Allocation Fund.

In Figure 9, we have reported the performance of the 60/40 portfolio for our universe of developed countries in the case when we hedge currency risks. We have also reported the performance of the risk parity strategy using the same universe. The annualized alpha and the tracking error volatility of the risk parity strategy with respect to the $60 / 40$ portfolio are $72 \mathrm{bps}$ and $7.80 \%$. The information ratio is then equal to $9.2 \%$. But the $60 / 40$ portfolio does not correspond to the traditional portfolio of large institutional investors in the Eurozone. The typical allocation is close to a $30 / 70$ portfolio. In this case, the outperformance of the risk parity is smaller and the information ratio becomes $5.4 \%$. But we could also use a 50/50 portfolio which is largely used by diversified fund and we obtain another story. In order to avoid these arbitrary choices of benchmark, the most rational choice is to use the market portfolio. In this case, we obtain an information ratio equal to $17.75 \%$.

\subsection{On the relationship between the market portfolio and long- term investment policy}

Long-term investment policy is generally defined by combining strategic asset allocation (SAA) and tactical asset allocation (TAA). Eychenne et al. (2011) explains that "SAA should 
Figure 9: Benchmarking a risk parity strategy

$60 / 40$

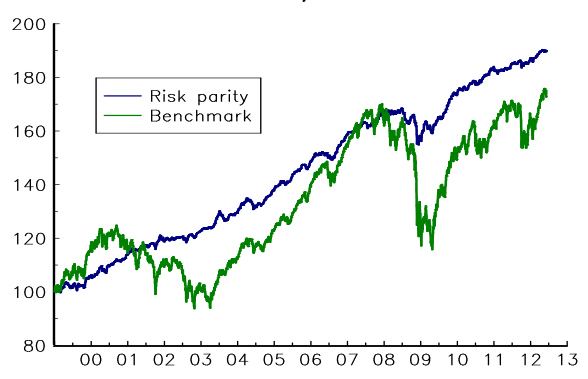

$50 / 50$

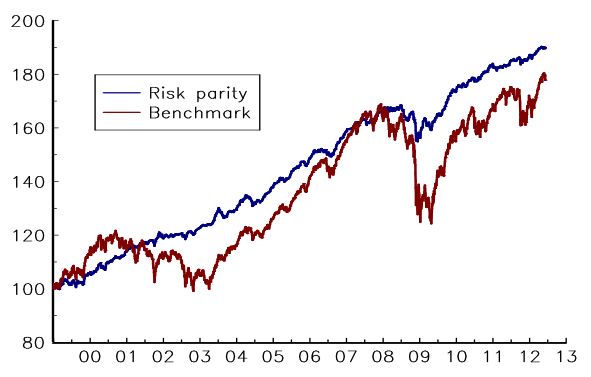

$30 / 70$

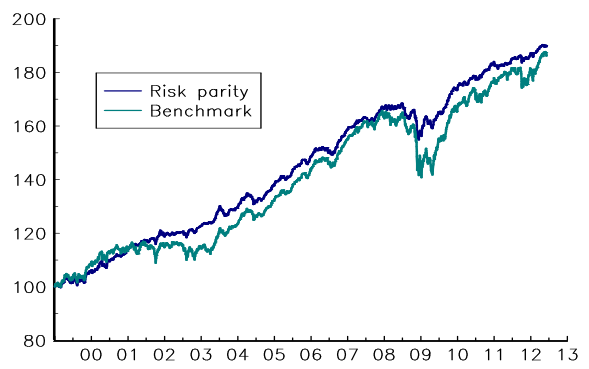

Market portfolio

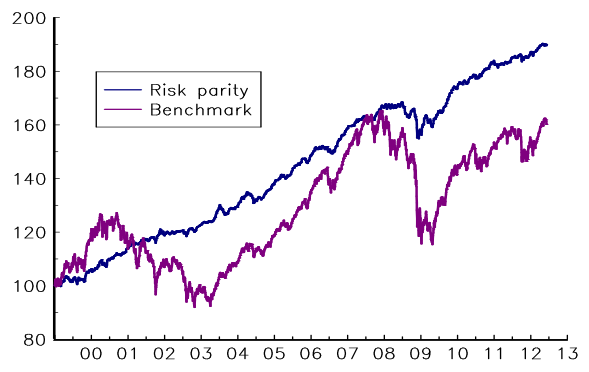

embody the long-run decisions based upon the assumption of stationary risk premiums given an economic scenario, while TAA should allow for adjusting to the business cycle within which risk premiums are time-varying". Strategic asset allocation is then the choice of equities, bonds (and other assets) that the investor wishes to hold on the long-run, usually from 10 to 50 years. Generally, the strategic asset allocation is revisited every year with small changes, except if the long-run economic scenario changes dramatically because of a structural break. The objective of the tactical asset allocation is to modify the strategic asset allocation in the short run in order to take into account the business cycle, the market sentiment or economic news. It implies that the current allocation is closer to the tactical asset allocation than to the strategic asset allocation. Generally, the current allocation is not exactly equal to the tactical asset allocation because of technical factors, decision lags and implementation difficulties ${ }^{16}$.

If changes in strategic asset allocation are not frequent and tactical asset allocation could only be done on a small part of the portfolio when the pension fund is large, long-term investment policy of such investors could be approximated as a constant mix strategy. As noticed by Sharpe (2010), many long-term investors are then contrarian. Let us consider for example the strategic asset allocation of the Norwegian Government Pension Fund Global (also known as the Norwegian petroleum fund) managed by Norges Bank Investment Management (NBIM). We can read in the website of NBIM the following objectives:

"The Government Pension Fund Global follows the investment strategy laid down by the Ministry of Finance in consultation with advisers including NBIM. The ministry has decided that 60 percent of the fund shall be invested in equities,

\footnotetext{
${ }^{16} \mathrm{~A}$ pension fund may manage several tens of billions of dollars. Changing the allocation is then done progressively in order to minimise market impacts.
} 
On the Market Portfolio for Multi-Asset Classes

35-40 percent in fixed-income securities and as much as 5 percent in real estate. The most important decision for the fund's future returns and risk levels is how much capital will be invested in equities, which are expected to have both higher returns and risk over time than the other asset classes. The fund shall only invest outside Norway".

The holdings of the Norwegian petroleum fund are reported in Table 4 . We verify that the difference of the weights with respect to the strategic allocation is small ${ }^{17}$. If we compare the weight of equities, we notice that the Norwegian petroleum fund has a positive bet on equity compared to the DC market portfolio. Moreover, Sharpe (2011) explains that the relative bets of long-term investment policy vary over time because of the time-varying nature of the market portfolio's allocation. Suppose for example that the long-term investment policy (resp. the market portfolio) consists in a 60/40 (resp. a 50/50) portfolio of stocks/bonds at time $t=0$. In this case, the long-term investor has a positive bet on equity compared to the market portfolio. Suppose now that the composition of the market portfolio becomes a $40 / 60$ portfolio at time $t=1$. If the long-term investment policy does not change, it means that the bet on equity is reinforced ${ }^{18}$. To be more concrete, a 60/40 asset mix policy was a negative bet on equity in 1999 , but a positive bet today.

Table 4: Allocation (in \%) of the Norwegian petroleum fund at the end of each quarter

\begin{tabular}{|c|c|c|c|c|c|c|c|c|c|c|c|}
\hline \multirow{2}{*}{\multicolumn{2}{|c|}{ Asset class }} & \multicolumn{2}{|c|}{2007} & \multirow{2}{*}{$\begin{array}{c}2008 \\
4 \mathrm{Q}\end{array}$} & \multirow{2}{*}{$\begin{array}{c}2009 \\
4 Q\end{array}$} & \multirow{2}{*}{$\begin{array}{c}2010 \\
4 Q\end{array}$} & \multicolumn{4}{|c|}{2011} & \multirow{2}{*}{$\begin{array}{c}2012 \\
1 \mathrm{Q}\end{array}$} \\
\hline & & $1 \mathrm{Q}$ & $4 \mathrm{Q}$ & & & & $1 \mathrm{Q}$ & $2 \mathrm{Q}$ & $3 \mathrm{Q}$ & $4 \mathrm{Q}$ & \\
\hline Equity & & 38.7 & 47.4 & 49.6 & 62.3 & 61.5 & 61.3 & 60.5 & 55.6 & 58.7 & 60.7 \\
\hline Bond & & 57.8 & 52.6 & 50.4 & 37.7 & 38.5 & 38.6 & 39.4 & 44.1 & 40.9 & 39.0 \\
\hline $\mathrm{RE}$ & & 0.0 & 0.0 & 0.0 & 0.0 & 0.0 & 0.1 & 0.1 & 0.3 & 0.3 & 0.3 \\
\hline \multirow[t]{2}{*}{ Equity } & $\mathrm{DC}$ & 65.8 & 64.6 & 48.1 & 50.2 & 50.8 & 51.6 & 50.7 & 44.9 & 46.8 & 48.8 \\
\hline & World & 69.6 & 69.9 & 53.1 & 56.7 & 57.8 & 58.5 & 57.4 & 51.5 & 53.3 & 55.5 \\
\hline \multirow[t]{2}{*}{ Bet } & $\mathrm{DC}$ & -27.1 & -17.2 & 1.5 & 12.1 & 10.7 & 9.7 & 9.8 & 10.7 & 11.9 & 11.9 \\
\hline & World & -30.9 & -22.5 & -3.5 & 5.6 & 3.7 & 2.8 & 3.1 & 4.1 & 5.4 & 5.2 \\
\hline
\end{tabular}

The market portfolio may help to characterize the bets of the strategic asset allocation. In the previous section, we have shown how to compute the risk premia $\pi^{\star}$. Let $\pi_{\mathrm{MP}}^{\star}$ (resp. $\pi_{\mathrm{SAA}}^{\star}$ ) be the risk premia priced by the market (resp. by the long-term investor) for the market portfolio (resp. for the strategic asset allocation policy). The differences between these two risk premia characterize the bets of the investor compared to the market. In Figure 10, we have reported these differences when the strategic asset allocation policy corresponds to different constant mix portfolios. It is interesting to notice that the absolute bet of equities over bonds may appear constant for the investor. In fact, the relative bets compared to the market portfolio vary over time as illustrated in Figure 10. For example, if we consider a 40/60 portfolio in the US, we have a positive bet on bonds except for a small period at the beginning of 2009. This bet reaches a maximum in July 2004. If we adopt the same asset mix policy in the Eurozone, the bet is negative today whereas it is positive for the US.

\footnotetext{
${ }^{17}$ The strategic allocation to equities was raised from 40 to 60 per cent in summer 2007 .

${ }^{18}$ This observation leads Sharpe (2010) to propose an adaptive asset allocation policy in order to maintain constant the relative bets.
} 
Figure 10: Differences between the bond risk premia $\pi_{\mathrm{SAA}}^{\star}$ and $\pi_{\mathrm{MP}}^{\star}$ (in bps)

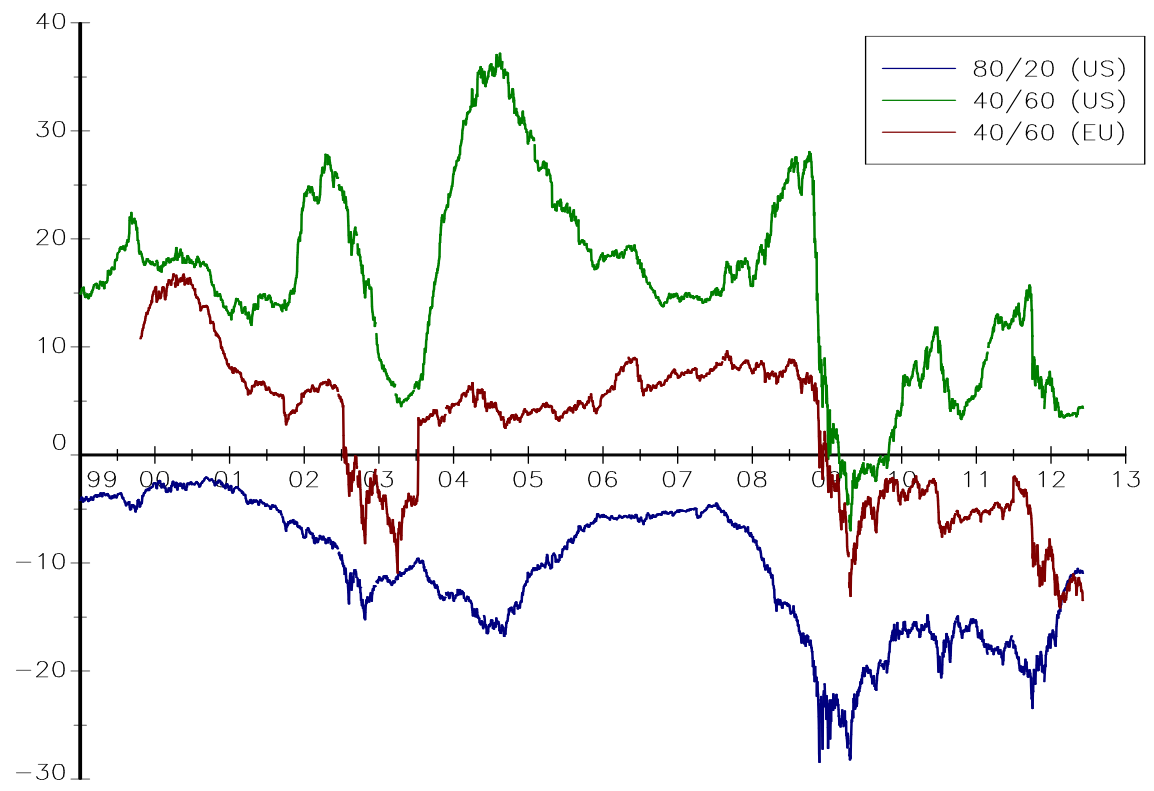

\section{Conclusion}

The objective of the paper was to compute some statistics about the market portfolio of stocks/bonds. We have shown how different are these portfolios according to the countries or regions. We also have illustrated how to deduce risk premia from these market portfolios and how to benchmark multi-assets funds. But one of the most interesting use remains the characterization of the relative bets of long-term investment policy.

This paper is also a call to create stock/bond indexes. The need of such indexes is crucial for all investors that manage multi-asset classes. Today, it is unthinkable to manage an equity or a fixed-income portfolio without a reference to a benchmark. And this benchmark is generally an index representing the market portfolio. It is time now for index providers to launch similar indexes representing the stock/bond market portfolio.

\section{References}

[1] Adler M. and Dumas B. (1983), International Portfolio Choice and Corporation Finance: A Synthesis, Journal of Finance, 38(3), pp. 925-984.

[2] Ambachtsheer K.P. (1987), Pension Fund Asset Allocation: In Defense of a 60/40 Equity/Debt Asset Mix, Financial Analysts Journal, 43(5), pp. 14-24.

[3] Asness C.S., Frazzini A. and Pedersen L.H. (2012), Leverage Aversion and Risk Parity, Financial Analysts Journal, 68(1), pp. 47-59.

[4] Black F. (1989), Universal Hedging: Optimizing Currency Risk and Reward in International Equity Portfolios, Financial Analysts Journal, 45(4), pp. 16-22. 
On the Market Portfolio for Multi-Asset Classes

[5] Black F., Jensen M.C. and Scholes M.S. (1972), The Capital Asset Pricing Model: Some Empirical Tests, in M.C. Jensen (Ed.), Studies in the theory of Capital Markets, Praeger Publishers Inc., pp. 79-121.

[6] Black F. and Litterman R.B. (1991), Combining Investor Views with Market Equilibrium, Journal of Fixed Income, 1(2), pp. 7-18.

[7] Black F. and Litterman R.B. (1992), Global Portfolio Optimization, Financial Analysts Journal, 48(5), pp. 28-43.

[8] Breeden D.T. (1979), An Intertemporal Asset Pricing Model with Stochastic Consumption and Investment Opportunities, Journal of Financial Economics, 7(3), pp. 265-296.

[9] Brinson G.P., Diermeier J.J. and Schlarbaum G.G. (1986), A Composite Portfolio Benchmark for Pension Plans, Financial Analysts Journal, 42(2), pp. 15-24.

[10] Brinson G.P., Singer B.D. and Beebower G.L. (1991), Determinants of Portfolio Performance II: An Update, Financial Analysts Journal, 47(3), pp. 40-48.

[11] Chaves D., Hsu J., Li F. and Shakernia O. (2011), Risk Parity Portfolio vs. Other Asset Allocation Heuristic Portfolios, Journal of Portfolio Management, 20(1), pp. 108118.

[12] Dimson E. and Mussavian M. (1999), Three Centuries of Asset Pricing, Journal of Banking \& Finance, 23(12), pp. 1745-1769.

[13] Eychenne K., Martinetti S. and Roncalli T. (2011), Strategic Asset Allocation, Lyxor White Paper, 6.

[14] Fama E.F. and MacBeth J.D. (1973), Risk, Return, and Equilibrium: Empirical Tests, Journal of Political Economy, 81(3), pp. 607-636.

[15] Fama E.F. and French K.R. (1996), The CAPM is Wanted, Dead or Alive, Journal of Finance, 51(5), pp. 1947-1958.

[16] Hereil P. and Roncalli T. (2011), Measuring the Risk Concentration of Investment Portfolios, Bloomberg Brief - Risk, July, pp. 8-9.

[17] Ibbotson R.G. and Fall C.L. (1979), The United States Market Wealth Portfolio, Journal of Portfolio Management, 6(1), pp. 82-92.

[18] Ibbotson R.G. and Siegel L.B. (1983), The World Market Wealth Portfolio, Journal of Portfolio Management, 9(2), pp. 5-17.

[19] Lewellen J. and Nagel S. (2006), The Conditional CAPM does not Explain AssetPricing Anomalies, Journal of Financial Economics, 82(2), pp. 289-314.

[20] Litterman R. (2003), Modern Investment Management: An Equilibrium Approach, Wiley.

[21] Lintner J. (1965), The Valuation of Risk Assets and the Selection of Risky Investments in Stock Portfolios and Capital Budgets, Review of Economics and Statistics, 47(1), pp. 13-37. 
[22] Maillard S., Roncalli T. and Teiletche J. (2010), The Properties of Equally Weighted Risk Contributions Portfolios, Journal of Portfolio Management, 36(4), pp. 60-70.

[23] Markowitz H. (1952), Portfolio Selection, Journal of Finance, 7(1), pp. 77-91.

[24] Merton R.C. (1973), An Intertemporal Capital Asset Pricing Model, Econometrica, $41(5)$, pp. $867-887$.

[25] Roll R. (1977), A Critique of the Asset Pricing Theory's Tests Part I: On Past and Potential Testability of the Theory, Journal of Financial Economics, 4(2), pp. 129-176.

[26] Sharpe W.F. (1964), Capital Asset Prices: A Theory of Market Equilibrium under Conditions of Risk, Journal of Finance, 19(3), pp. 425-442.

[27] Sharpe W.F. (2010), Adaptive Asset Allocation Policies, Financial Analysts Journal, $66(3)$, pp. $45-59$.

[28] Tobin J. (1958), Liquidity Preference as Behavior Towards Risk, Review of Economic Studies, 25(2), pp. 65-86. 